\title{
MATERIAIS GEMOLÓGICOS COMO REFERÊNCIA NO DESENVOLVIMENTO DE DIFERENTES SUPERFÍCIES
}

\author{
Camila Zappe Pereira \\ Universidade Federal de Santa Maria \\ mila-zappe@hotmail.com \\ Reinilda de Fátima Berguenmayer Minuzzi \\ Universidade Federal de Santa Maria \\ reibmin@yahoo.com.br
}

Resumo: A presente pesquisa teve o propósito de desenvolver conjuntos de estampas têxteis a partir dos materiais gemológicos como referência criativa. Este estudo acadêmico manteve ênfase teórica em Design de Superfície e investigou questões que permeiam Gemologia, um termo utilizado internacionalmente para designar a ciência responsável por identificar, classificar e avaliar gemas - comumente denominadas pedras preciosas. Parte da finalidade desta investigação destacou as recorrentes aplicações existentes destes materiais, analisando particularmente a incorporação das gemas como temática de criação. A parcela prática da pesquisa foi desenvolvida a partir de registros fotográficos dos materiais gemológicos encontrados no Estado do Rio Grande do Sul. Todas as estampas foram desenvolvidas com imagens autorais das gemas, o que mantém a singularidade da pesquisa e garante exclusividade aos resultados finais. No transcorrer deste estudo objetivou-se, sobretudo explorar as potencialidades visuais dos materiais gemológicos, as composições resultantes deste processo foram testadas sobre diversas superfícies e inseridas no segmento têxtil do design de superfícies por meio de uma coleção feminina voltada à moda praia.

Palavras-chave: Design de Superfície, Estamparia, Materiais Gemológicos.

\begin{abstract}
This research had the purpose to develop sets of textile prints from the gemological materials as a creative reference. This academic study remained theoretical emphasis on Surface Design and investigated issues that permeate Gemology, a term used internationally to describe the science responsible for identifying, classifying and evaluating gemstones - precious stones commonly called. Part of the purpose of these investigations highlighted the applicants existing applications of these materials, particularly analyzing the incorporation of gems as a theme of creation. The practical part of the research was developed from photographic records of gemological materials found in the Rio Grande do Sul State, all prints were developed with copyright images of gems, what keeps the uniqueness of the research and guarantees exclusivity to the final results. In the course of this study aimed to explore particularly the visual potential of
\end{abstract}


gemological materials, wherein this process the resulting compositions were tested on various surfaces, and inserted in the textile segment surface design through a women's swimwear collection.

Keywords: Surface Design, Printing, Gemological Materials.

\section{INTRODUÇÃO}

A presente pesquisa desenvolveu-se por meio de três momentos. 0 primeiro contém uma introdução conceitual acerca da gemologia; nesta etapa apresentam-se algumas definições do universo gemológico, exemplificam-se aplicações da gema como produto e como temática de criação no cenário têxtil do design. No segundo momento demonstra-se a etapa de experimentação da gema como referência no desenvolvimento de diferentes superfícies e, por fim, no terceiro, as alternativas têxteis geradas, as estampas desenvolvidas e aplicação dos padrões em peças moda praia para vestuário feminino.

O interesse pessoal pelas gemas e pedras lapidadas surgiu ao residir na cidade de Soledade, localizada no Estado do Rio Grande do Sul, intitulada como "A Capital das Pedras Preciosas". Durante este período nesta localidade o contato com as gemas foi constante em função do comércio local e das inúmeras empresas destinadas a lapidaria, lojas e departamentos especializados em materiais de valores gemológicos.

Somente há pouco tempo surgiu a oportunidade de incorporar a gemologia a uma pesquisa acadêmica. A primeira experiência que abordou esta temática ocorreu durante a graduação. Os primeiros estudos envolvendo os materiais gemológicos eram inteiramente práticos e manuais, sendo que as estampas eram desenvolvidas a partir de colagens de imagens impressas de gemas encontradas digitalmente. Os resultados desta experiência inicial foram muito importantes e significativos, em decorrência deste primeiro estudo desenvolveu-se o presente projeto, abordando com mais ênfase e aprofundamento a mesma referência criativa.

Ao inserir na atual etapa acadêmica os materiais gemológicos como temática de estudo, objetivou-se uma pesquisa prático-teórica na área do Design de Superfície que buscasse novas possibilidades de investigação desta matéria prima. Existentes em várias cidades do Rio Grande do Sul, as gemas tema deste projeto são recursos naturais extraídos há décadas. Estes materiais são comercializados em geral através de produtos usuais, como joias e objetos decorativos. Esta pesquisa pretende demonstrar às regiões produtoras uma nova possibilidade de emprego destes recursos naturais, ampliando a utilização destes por meio de outras potencialidades, como a estamparia e o Design de Superfície.

Embora ampliação das possibilidades comerciais destes materiais possa ser inovador, as gemas vêm sendo um tema abordado em alguns segmentos do Design de Superfície há alguns anos no Brasil e no exterior. No decorrer do projeto procurou-se exemplificar algumas produções têxteis realizadas a partir da gema como temática de criação; porém, além de apenas seguir algumas tendências do mercado ao desenvolver e aplicar uma coleção de estampas, este projeto intencionou investigar as múltiplas possibilidades que emergem dos materiais gemológicos.

Esta pesquisa é fruto do projeto para pós-graduação no campo do Design de Superfície e grande parte de seus resultados concretizaram-se por meio das 
oportunidades e disciplinas ao longo do Curso. No decorrer das experiências acadêmicas foram realizadas experimentações dos materiais gemológicos sobre diversas superfícies como papel, MDF, vidro e tecido. Depois de muitos testes compondo diferentes superfícies através da gema como referencial criativo optou-se por focar os resultados finais da pesquisa no segmento têxtil desenvolvendo estampas para uma coleção feminina moda praia. A presente pesquisa destaca o universo gemológico, amplia os métodos de exploração dos recursos naturais e procura divulgar e demonstrar novas possibilidades às regiões que comercializam as gemas e a pesquisadoras da área.

\section{MATERIAIS GEMOLÓGICOS: CONCEITOS E APROXIMAÇÕES COM DESIGN}

A gemologia é um segmento que parte da geologia, ciência que estuda a estrutura, composição e propriedades da terra. Baseada no ramo das ciências geológicas, a gemologia é considerada uma ciência aplicada destinada a estudar o ramo específico das gemas. De acordo com Schumann (2006, p. 10) "popularmente, pedras é o nome coletivo para todos os constituintes sólidos da crosta da Terra. Para o joalheiro uma pedra é uma gema". O autor completa que "na ciência da Terra, Geologia, não se fala em pedras, mas em rochas e minerais" reafirmando o que muitas bibliografias relatam. Schumann ainda afirma que a designação "pedras preciosas" ainda é usada no comércio, mas "não é uma expressão correta porque muitas pedras chamadas 'semipreciosas' são mais valiosas que as 'preciosas'. O melhor termo para todas é gema" (SCHUMANN, 2006, p. 10).

Tratando-se ainda de nomenclaturas, de acordo com o Instituto Brasileiro de Gemas e Metais Preciosos (IBGM, 2009, p. 15) existem definições para cada tipo de gema "os materiais gemológicos normalmente encontrados no Brasil ou que são comumente comercializados possuem definições e nomenclaturas indicadas em normas técnicas específicas nacionais - ABNT e internacionais". Destacam-se no Quadro 1 as principais nomenclaturas e definições de gemas elaboradas a partir do Manual Técnico de Gemas do IBGM.

Quadro 1 - Principais Nomenclaturas e Definições

\begin{tabular}{|l|l|}
\hline Gema Natural & $\begin{array}{l}\text { Materiais gemológicos formados essencialmente pela natureza, formação } \\
\text { magmática, sedimentar ou metamórfica. Pode ser uma substância natural } \\
\text { orgânica ou uma substância natural inorgânica }\end{array}$ \\
\hline Gema Natural Orgânica & Substância formada pela natureza de origem animal ou vegetal \\
\hline Gema Natural Inorgânica & Substância formada pela natureza de origem mineral \\
\hline Gema Artificial & $\begin{array}{l}\text { Substância criada e fabricada pelo homem em laboratório que não possui } \\
\text { nenhuma semelhança com as gemas naturais }\end{array}$ \\
\hline Gema Sintética & $\begin{array}{l}\text { Substância produzida pelo homem em laboratório que possui } \\
\text { semelhanças similares com as gemas naturais }\end{array}$ \\
\hline Gema Composta & $\begin{array}{l}\text { Materiais gemológicos compostos de duas ou mais partes unidas de } \\
\text { gemas naturais, sintéticas ou artificiais }\end{array}$ \\
\hline Gema Tratada & $\begin{array}{l}\text { Gemas com melhoramentos feitos em laboratório, por tingimento, } \\
\text { tratamento térmico, irradiação gama, entre outros }\end{array}$ \\
\hline
\end{tabular}

Fonte: Elaborado pelo autor, com base na pesquisa realizada no IBGM (2009, p. 15).

O acesso e disponibilização de novos minerais e depósitos gemológicos cresceu juntamente com a evolução das civilizações, assim, as gemas e peças de adorno geradas a partir destas foram sendo nitidamente introduzidas ao cotidiano dos povos. 
Woodward (2001, p. 10) destaca como exemplo dessa inserção o aumento do comércio organizado de diamantes, safiras e rubis provenientes do Sri Lanka, fonte de rendimento de todo o Estado percebido em registros de mais de 2000 anos.

A gema que hoje é lapidada, durante a XVIII Dinastia do Egito foi esculpida para retratar a rainha Nefertiti como uma demonstração de riqueza. Desde os tempos remotos, Woodward (2001, p. 9) descreve que "as pedras preciosas foram usadas como símbolos de poder divino e terreno, como testemunho de riqueza e status [...] A beleza e a atração pelo ouro e pedras preciosas inspirou um florescimento precoce das artes decorativas". Gola (2013, p. 24) complementa que, ao que parece, foi a necessidade do homem de adornar-se que incluiu objetos de ourivesaria e de joalheria como uma das formas de arte.

Percebe-se que além da função estética das gemas foi construída uma história de fortalecimento do comércio e da sociedade que pode ser contada e ilustrada pelo decorrer dos séculos. Analisando a inserção da gemologia desde as civilizações antigas pode-se perceber na afirmação de Gola $(2013$, p. 05) que na história da humanidade "pelas variadas funções que assume em diferentes épocas e culturas distintas, a joia sempre esteve presente. É moeda universal que não perde seu valor material, é documento que resiste ao tempo, é patrimônio impregnado de sentimentos". Atualmente os mesmos valores como adorno, riqueza e status ainda são agregados a esses materiais gemológicos e consequentemente aplicados aos produtos.

Além de peças de adorno pessoal provenientes da joalheria, o designer de produto é responsável por outras incorporações deste material, no segmento de decoração, por exemplo, onde a aplicação da gema é menos usual, mas permite amplas possibilidades autênticas. Por meio de referências visuais (Figura 1) percebemse alguns produtos gemológicos destinados à decoração como abajures, maçanetas, cadeiras, utensílios de cozinha e detalhes que compõem ambientes variados.
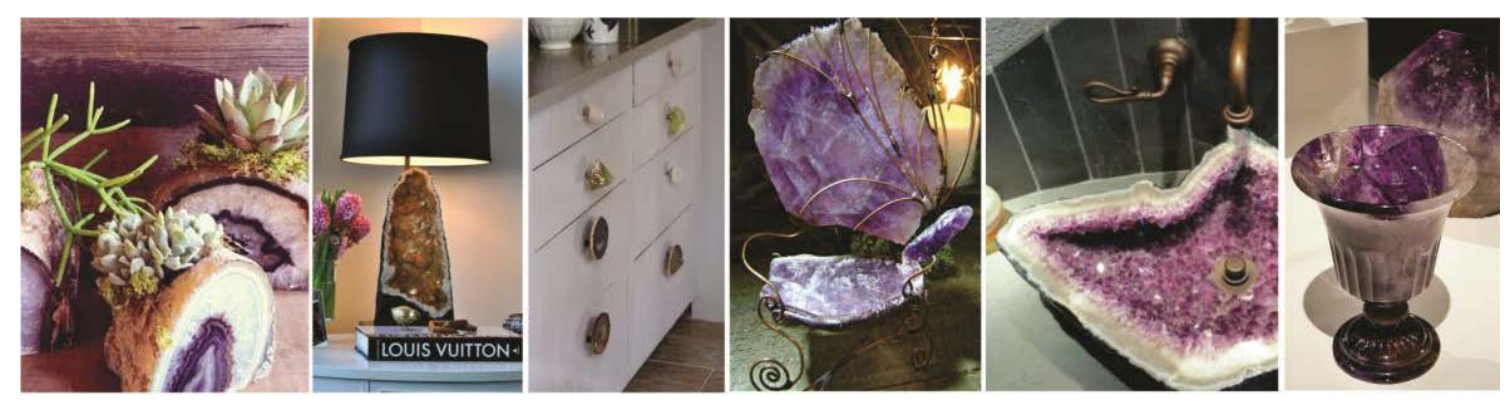

Figura 1 - Materiais Gemológicos na Decoração.

Fonte: Montagem elaborada pelas autoras, 2014.

Acredita-se que ao explorar a gemologia como referencial criativo as possibilidades provenientes naturalmente da terra se ampliem, como afirma o designer Richard Weston em seu website (2015) "a natureza é o maior artista vivo da Terra. Sempre foi. Sempre será". Buscou-se demonstrar a variedade de soluções criativas e o potencial que se pode usufruir a partir da gama existente de materiais gemológicos. O designer Richard Weston aprecia a veracidade da semelhança com o referencial. Esta aproximação é visível em suas coleções de lenços (Figura 2). Como professor, artista e criador, Richard trocou sua paixão da arquitetura pela natureza e solucionou através de uma ferramenta digital um anseio artístico. 
Ainda no segmento têxtil a temática gemológica encontra-se nos lenços desenvolvidos por Jennifer Altman (Figura 2). A designer trabalha com joias e é fotógrafa, em seu processo aplica seus registros fotográficos dos materiais gemológicos em tecidos de crepe ou seda. A intenção segundo Altman é amplificar o máximo possível a beleza natural das gemas para estender o uso das joias, antes frias e pontiagudas ao toque macio do lenço. Além do tecido, o estilista Karl Lagerfeld da Chanel, desenvolveu toda um desfile de moda que fez menção à gema como referencial criativo no ano de 2012. Em Paris, no Le Grand Palais, a marca Chanel apresentou o primeiro desfile dedicado inteiramente à gemologia. A dedicação ao tema não se restringiu à decoração do ambiente, as formas orgânicas e geometrizadas estavam presentes nos acessórios, as bolsas e pulseiras representavam de maneira fidedigna as incrustações naturais das gemas brutas. Na Figura 2, respectivamente, detalhes do desfile da Chanel, lenços por Richard Weston e por Jennifer Altmn.
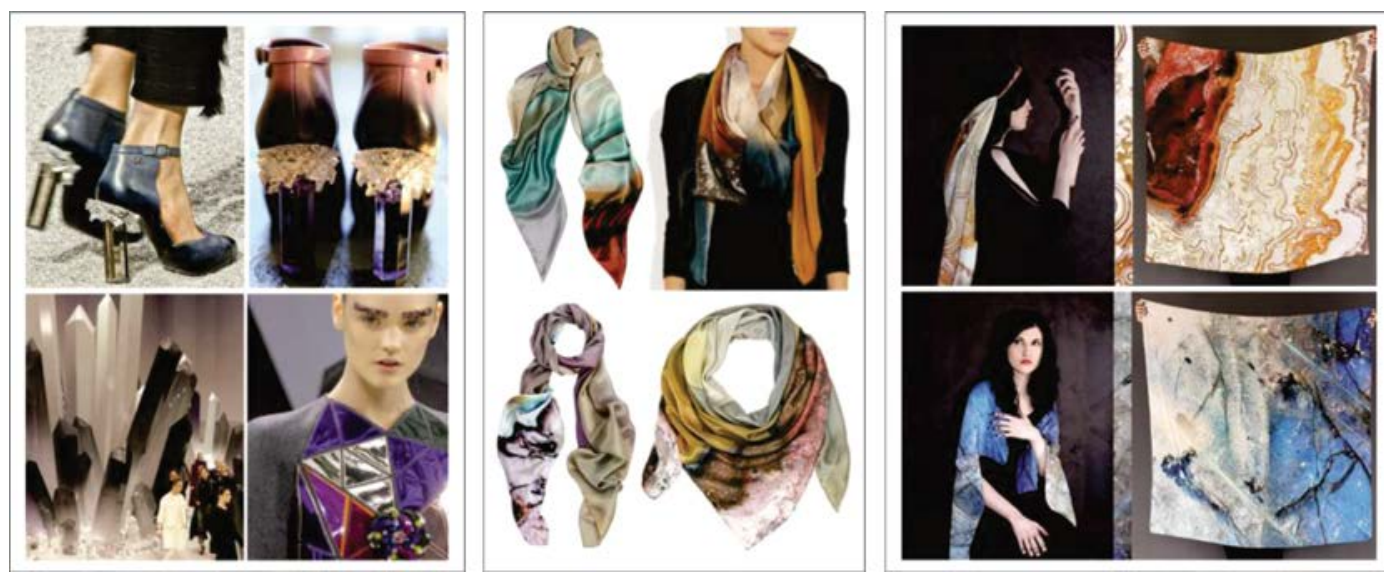

Figura 2 - Gema como referencial criativo I.

Fonte: Montagem elaborada pelas autoras, 2014.

Entre outros exemplos da gema como referencial criativo no segmento têxtil está Philip Lim. O designer denotou de maneira muito discreta a inserção dos elementos gemológicos em sua coleção. As principais peças de sua coleção destacam estampas digitais e bordados em uma paleta branca, preta, com tons de verdes e azuis (Figura 3). No Brasil o destaque é para as coleções têxteis das marcas Alessa e Água de Coco. Alessa já desenvolveu mais de um desfile com esta temática, em 2011, por exemplo, a designer destacou gemas brutas em vestidos drapeados, em um segundo momento, em 2015, suas estampas digitais de fundo preto impressas em cetim e seda, ressaltavam gemas lapidadas e joias em grandes padronagens. A marca Água de Coco em 2014 fez uma homenagem ao Brasil, destacando todas as suas riquezas, dentre elas, as gemas. Grande parte das peças - como biquínis, peças únicas, saias e vestidos - além de ter a temática estampada, destacavam aplicações de gemas ao longo das modelagens. Na Figura 3, respectivamente, Philip Lim, Alessa e Água de Coco. 

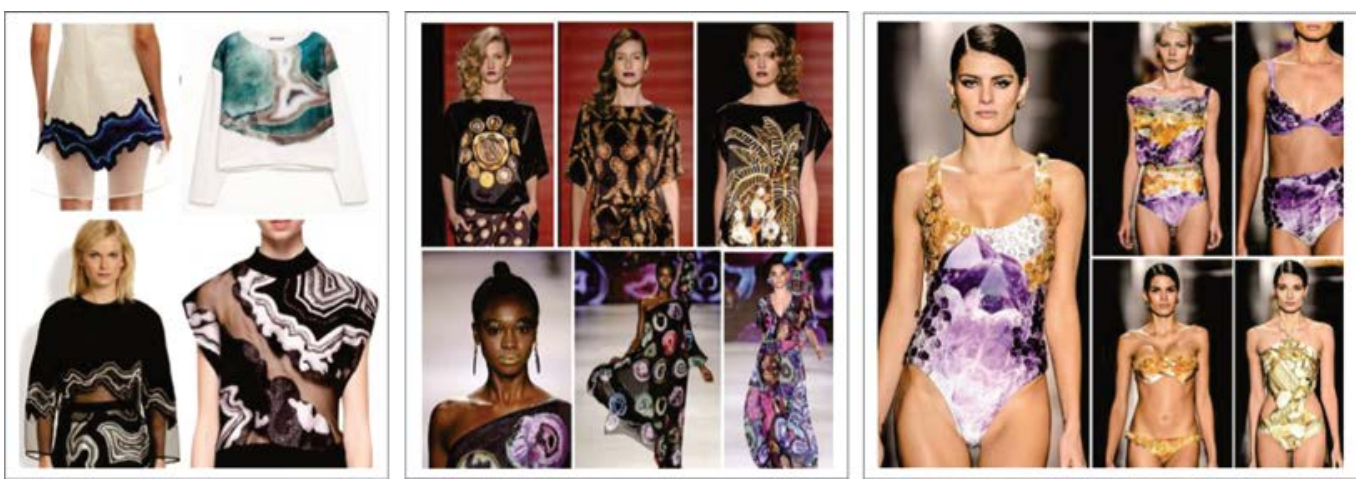

Figura 03 - Gema como referencial criativo II.

Fonte: Montagem elaborada pelas autoras, 2014.

\section{SUPERFÍCIES GEMOLÓGICAS: EXPERIMENTAÇÕES EM DIVERSOS SUPORTES}

Os materiais gemológicos são uma temática pesquisada desde 2012, um estudo que iniciou na graduação e teve prosseguimento na pós-graduação. Nesta etapa exemplifica-se o desenvolvimento das investigações geradas neste período, com descrição dos processos criativos, estampas criadas, aplicações em diferentes produtos e outras questões pertinentes ao percurso da pesquisa.

A escolha da gema como referencial criativo na composição de estampas ocorreu pela primeira vez no ano de 2012. Realizava-se uma busca digital por imagens de materiais gemológicos que, após uma primeira seleção, eram dispostos em diferentes tamanhos em uma página $A 3$, posteriormente impressa em cores. $O$ processo manual contemplava o recorte de cada gema e colagem destas, de forma que, se formasse uma espécie de módulo. As colagens resultantes dessa parcela manual eram escaneadas e trabalhadas digitalmente (Figura 4).
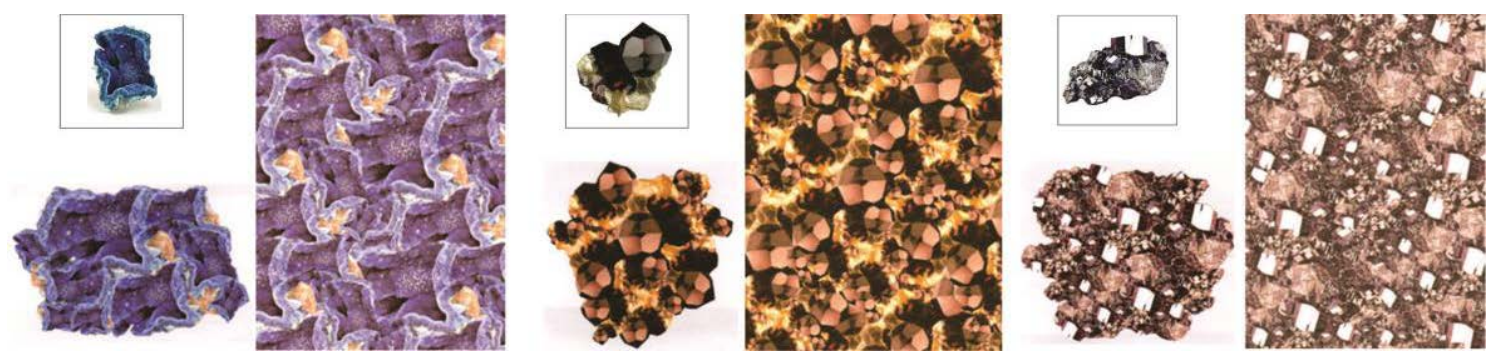

Figura 04 - Experimentações I.

Fonte: Elaborado pelas autoras, 2014.

As primeiras experimentações foram impressas em papel fotográfico e, embora as imagens utilizadas sejam de domínio público, destaca-se positivamente o processo criativo e considera-se o resultado plástico visualmente interessante. Ao todo cerca de vinte estampas foram desenvolvidas, cada uma proveniente do processo criativo baseado em uma gema, nacional ou internacional. Alguns resultados foram gerados a partir dessa primeira pesquisa, dentre eles a premiação na área (Figura 5). 

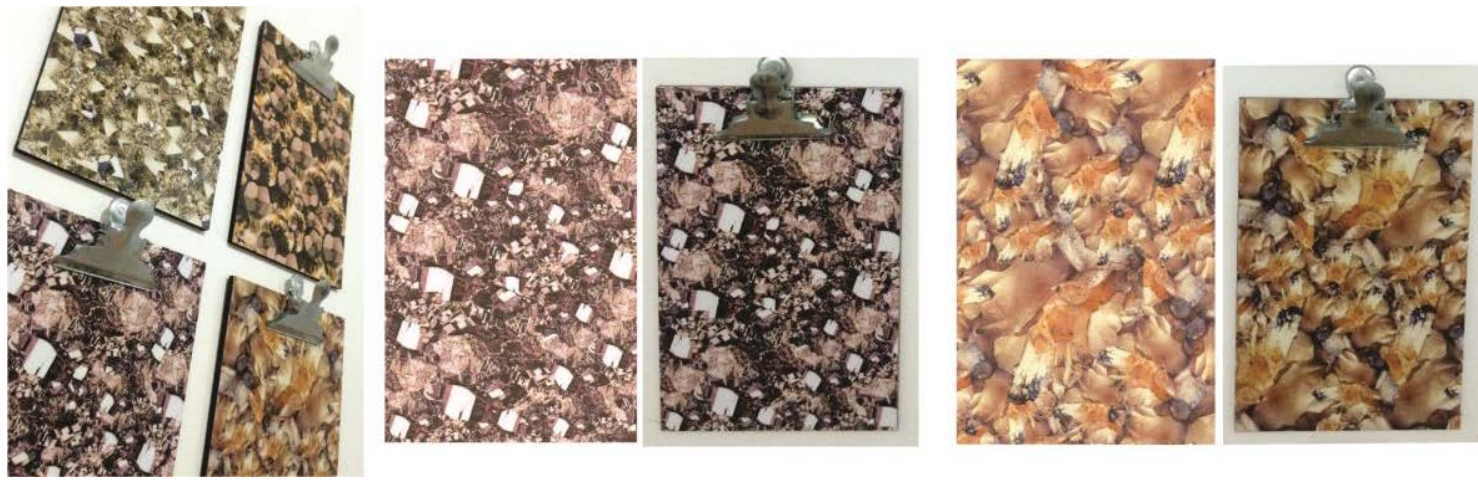

Figura 05 - Experimentações II.

Fonte: Elaborado pelas autoras, 2014.

Com estas primeiras experiências percebeu-se que existiam algumas lacunas a serem corrigidas, porém um grande espaço para crescimento e melhora da pesquisa. A procedência da imagem da gema e origem do próprio material gemológico não era levada em consideração, um aprofundamento teórico também era necessário. Optouse por dar continuidade aos estudos referentes aos materiais gemológicos com a proposta do presente projeto. O primeiro produto desenvolvido nesta nova etapa acadêmica foi um conjunto de seis porta-copos e uma bandeja de vidro (Figura 6), as peças foram realizadas manualmente fazendo uso de impressão sobre papel fotográfico.
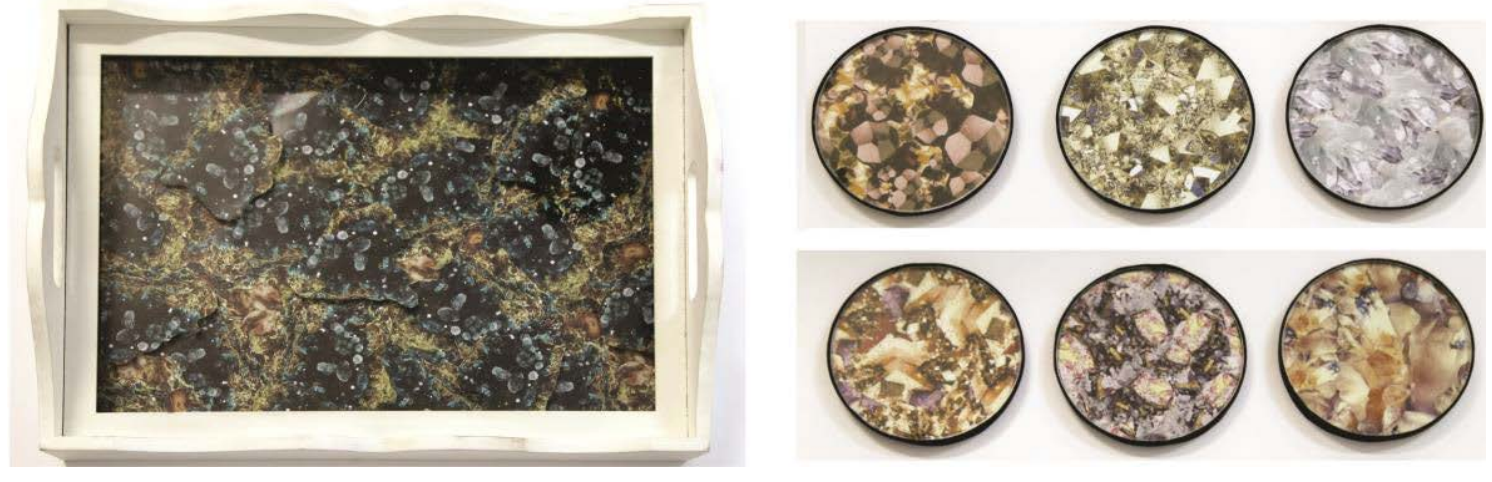

Figura 6 - Experimentações III.

Fonte: Elaborado pelas autoras, 2014.

A bandeja foi produzida em MDF e possui um tampo de vidro, a estampa foi inserida na parte de dentro do produto. Além do fundo estampado existem recortes de gemas em um segundo nível de altura, na intenção de destacar a questão de profundidade, com planos sobrepostos. Os porta-corpos são de vidro e possuem a base de EVA, entre esses dois materiais aplicou-se a estampa impressa em papel fotográfico.

No decorrer do segundo semestre de 2014 a oportunidade de conhecer algumas empresas de revestimento do Estado de Santa Catarina. Após visita às empresas de revestimentos catarinenses, optou-se por inserir a gema como temática na superfície de vidro, sendo desenvolvidos três projetos (Figura 7) cada um deles formado por nove peças $10 \times 10 \mathrm{~cm}$. 

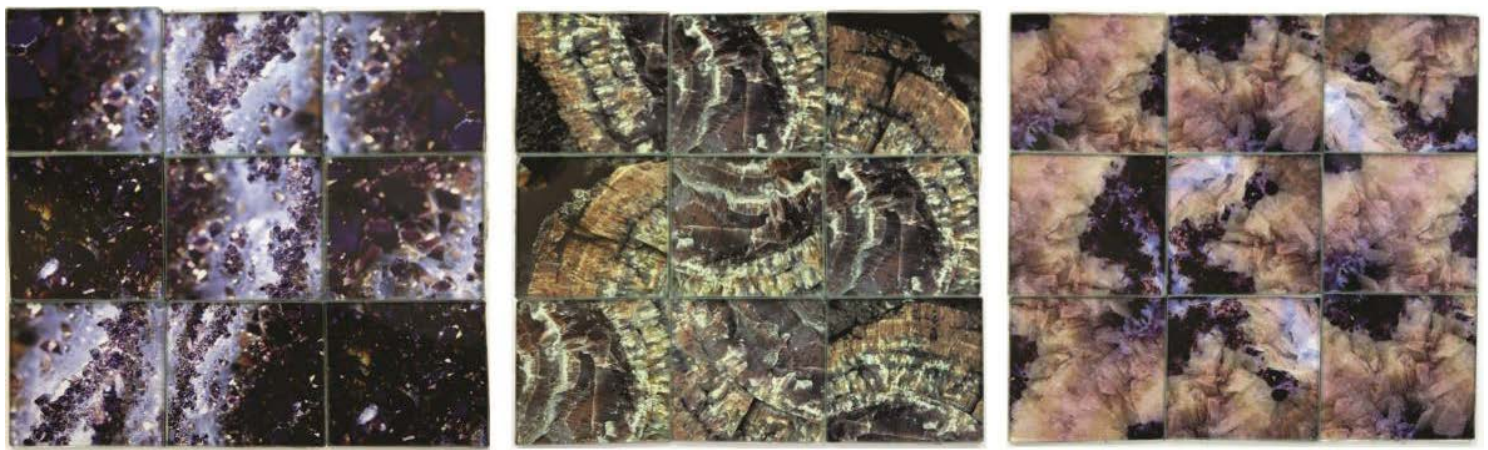

Figura 7 - Experimentações em vidro. Revestimentos I.

Fonte: Elaborado pelas autoras, 2015

Nestes primeiros resultados fez-se uso de imagens de ametista e madeira petrificada de domínio público disponibilizadas digitalmente, aproximadamente quatro recortes digitais eram feitos e impressos várias vezes, para que depois de testes manuais se percebesse quais peças formariam um padrão melhor. $O$ objetivo com este projeto inicial era voltado ao setor de revestimentos com um produto para fins decorativos. Cada vidro $10 \times 10 \mathrm{~cm}$ formaria uma peça $30 \times 30 \mathrm{~cm}$, composta por nove unidades menores, possibilitando adquirir vários conjuntos para revestir detalhes de ambientes variados. Além do padrão formado dentro da peça $30 \times 30 \mathrm{~cm}$, pelos nove vidros, a disposição de cada unidade configura diversos resultados.

Em busca de dar continuidade à investigação prática na área de revestimento em vidro, em uma etapa mais avançada da presente pesquisa, alguns pontos falhos percebidos com as primeiras experimentações foram alterados. Procurou-se por uma empresa especializada em vidros para obter além de peças melhores acabadas, formatos diferenciados. Além disso, almejava-se também empregar mais singularidade às peças, de maneira que, as imagens utilizadas não poderiam mais ser de domínio público. O projeto inicialmente realizado por meio de uma proposta da aula foi importante, mas experimental.

A principal finalidade sempre foi transformar os materiais gemológicos em referencial criativo, porém, de forma única e singular. Pensando nisto e analisando os primeiros resultados, realizou-se uma pesquisa de campo em algumas cidades do Rio Grande do Sul, com o objetivo de registrar pessoalmente as gemas encontradas no Estado. Deste modo, além de providenciar formatos diferenciados com bom acabamento, as imagens utilizadas no desenvolvimento das futuras peças seriam exclusivas, garantindo resultados particulares.

Após a seleção dos registros fotográficos realizados em pesquisa de campo, e como desenvolvimento de modelos para futuros protótipos, a foto original de uma gema era impressa, recortada e aplicada manualmente com cola para vidro nas peças encomendadas. Na Figura 8, exemplos de experimentações com vidros nos formatos hexagonal, losangular, triangular, retangular, e quadrangular desenvolvidos por meio deste processo. 


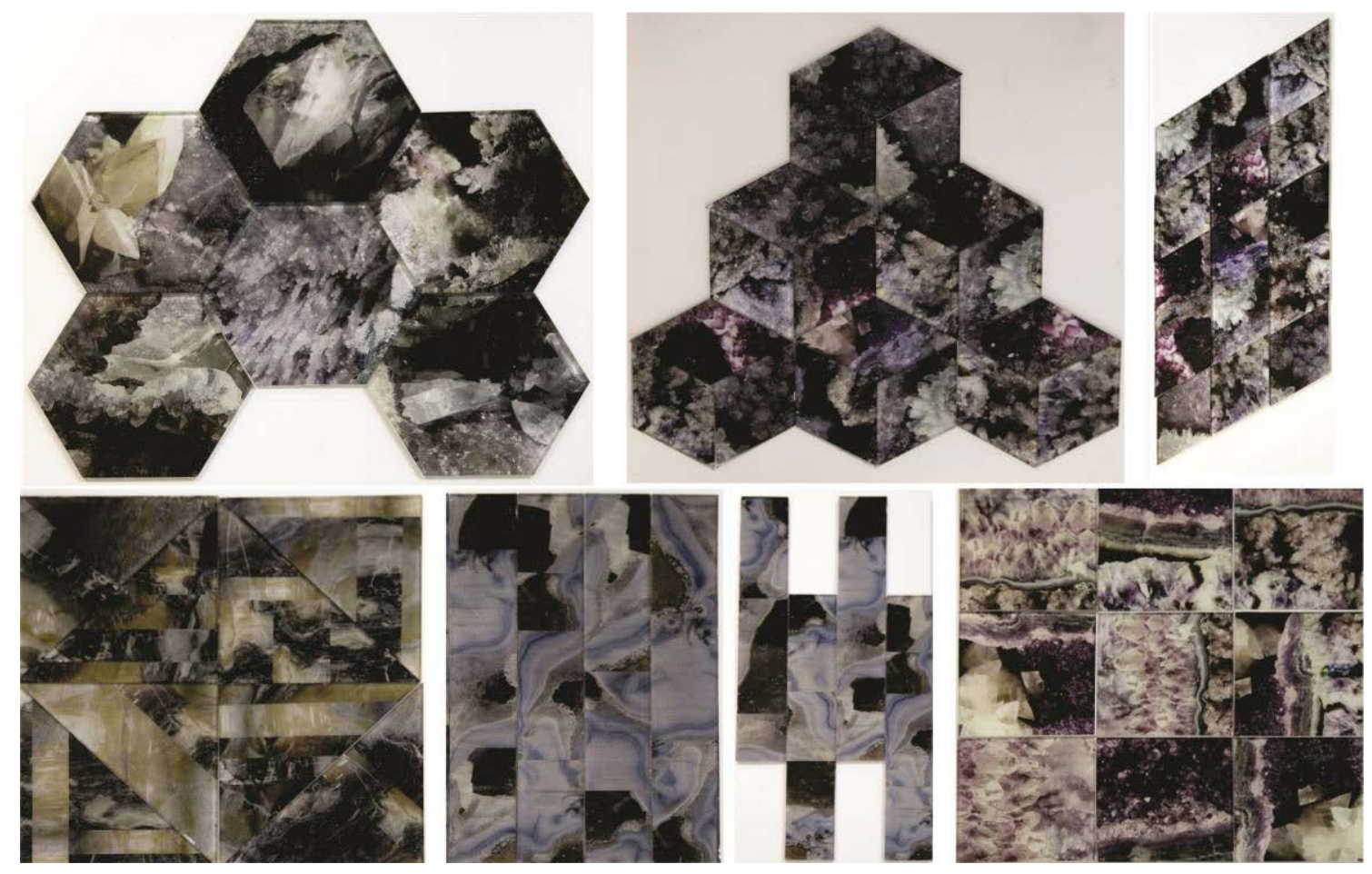

Figura 8 - Experimentações em vidro. Revestimentos II. Fonte: Elaborado pelas autoras, 2014.

Além dos testes realizados manualmente, um conjunto de noves peças, de formato quadrangular, foi desenvolvido através de processo industrial com impressão sobre vidro. Até então as experimentações realizadas são de peças adequadas à decoração de paredes.

Pensando em investigar outras possibilidades optou-se por desenvolver outros dois projetos. $\mathrm{O}$ primeiro destinado ao revestimento de piso trata-se de um conjunto de nove peças $15 \times 15 \times 4 \mathrm{~cm}$ em MDF preenchidas com imagens de diversas gemas dispostas em diferentes níveis de altura, para simular profundidade. $O$ intuito é que as peças fossem aplicadas a uma abertura no chão e sobre a totalidade da área se dispusesse um vidro próprio para piso (Figura 9).

Também fazendo uso do MDF como material principal, desenvolveu-se um projeto para revestimento e decoração de paredes formado por 30 peças $10 \times 10 \mathrm{~cm}$ em formato losangular. Neste segundo projeto (Figura 9) escolheu-se a gema de ametista para compor as superfícies. A composição foi dividida em três grupos, a cada dez peças uma tonalidade do material gemológicos. A metodologia do projeto se deu com a seleção das fotos originais, escolhas das imagens finais, impressão sobre papel fotográfico, encomenda e acabamento das peças em MDF com tinta e papel contact preto fosco e aplicação da imagem na peça. 

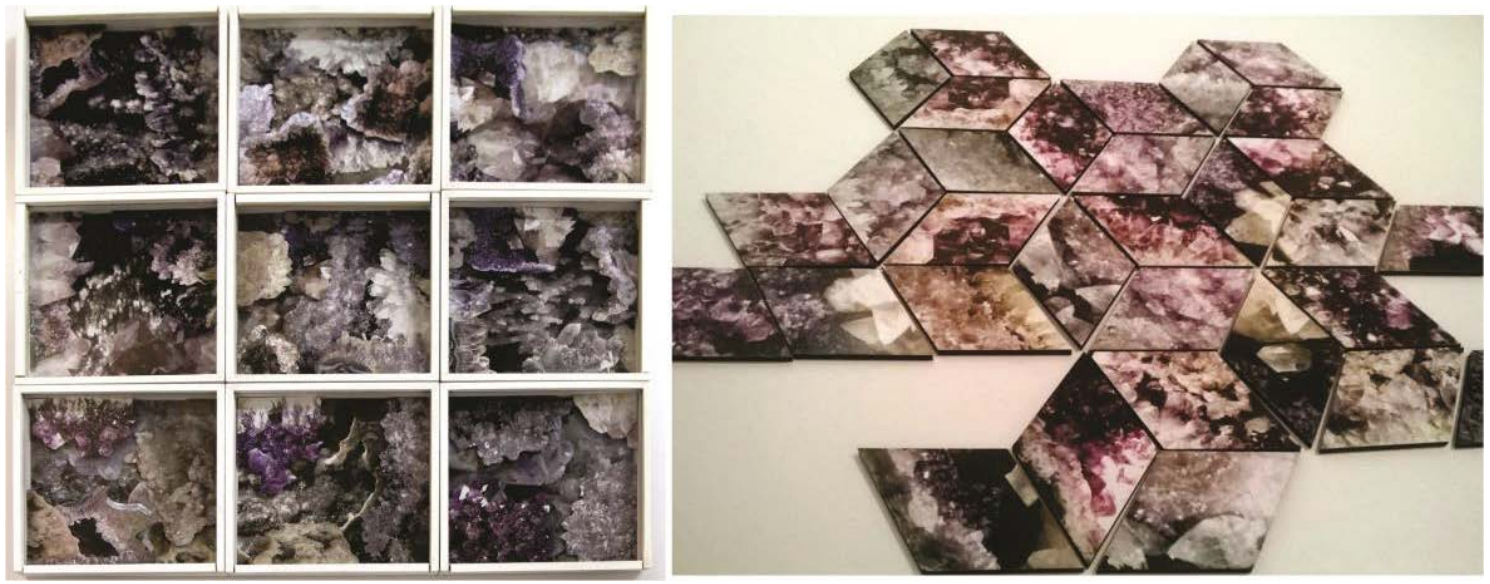

Figura 9 - Experimentações em MDF. Revestimentos I.

Fonte: Elaborado pelas autoras, 2015.

Acredita-se que os objetivos referentes à experimentação das gemas como referência criativa sobre diversas superfícies tenha sido um requisito alcançado e concluído de maneira positiva. Desenvolveu-se uma pesquisa prática enriquecedora, as experimentações realizadas possibilitam outros cursos de investigação e com certeza resultados futuros. Os testes apresentados à banca avaliadora foram satisfatórios e precedem a pesquisa da gema como referencial no segmento têxtil do design. Além de testes em diferentes tecidos, a proposta na próxima etapa da pesquisa prática consistiu em compor uma coleção de estampas destinadas à moda praia com aplicações em peças como biquíni, maiô e collant.

\section{DESIGN TÊXTIL: COLEÇÃO PRECIOSIDADES}

Conseguinte às experimentações, segue a pesquisa referente à gema como referencial criativo no desenvolvimento de uma coleção de estampas para o segmento moda praia do design têxtil. A imagem da gema é a referência criativa no desenvolvimento dos padrões a serem estampados, portanto, prezando pela singularidade desta pesquisa as fotografias utilizadas neste estudo são todas autorais, garantindo exclusividade das estampas desde o processo inicial. Depois da captura fotográfica dos materiais gemológicos, que ocorreu nas cidades de Gramado e Soledade no Estado do Rio Grande do Sul, o processo de desenvolvimento criativo inicia com a seleção dos melhores registros das gemas. As fotografias escolhidas geram estampas por meio de dois processos de recorte e colagem, um inteiramente manual (Figura 10) e outro através da colagem digital (Figura 11), quando o registro da gema é manipulado diretamente no computador. 

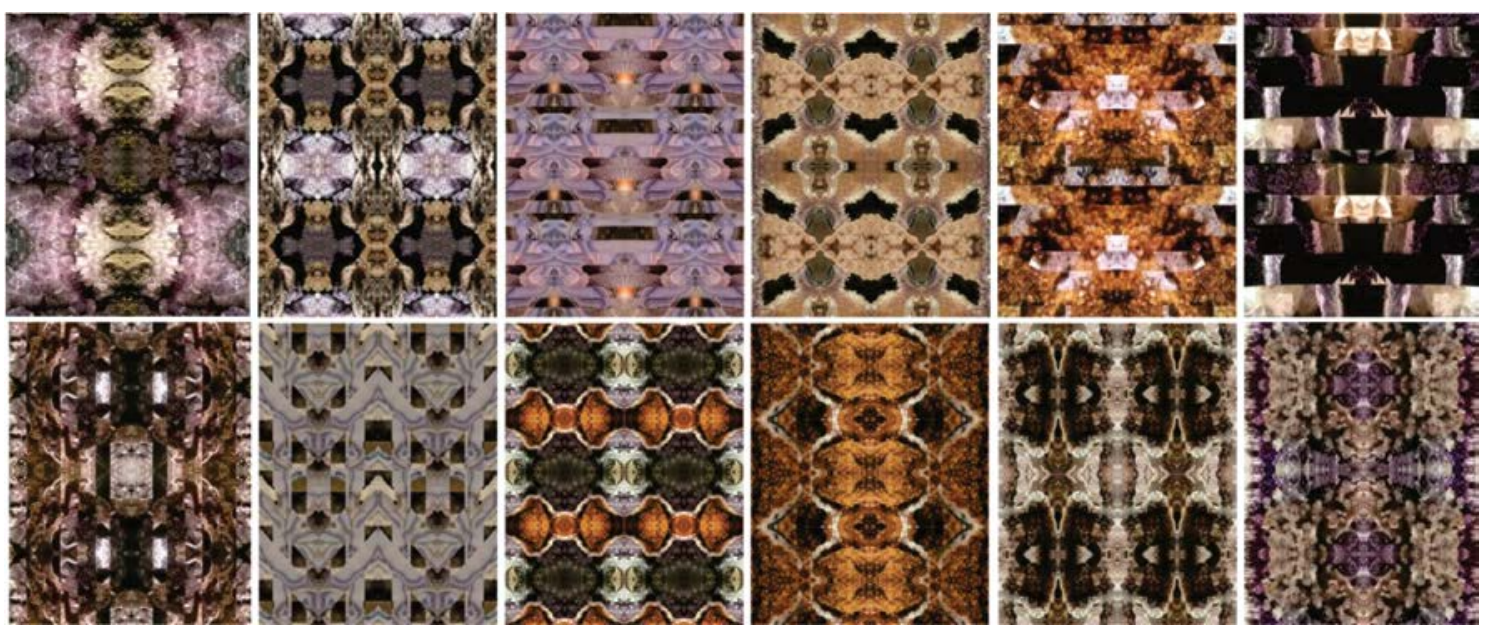

Figura 10 - Resultados - Processo Manual.

Fonte: Elaborado pelas autoras, 2015.

A geração de alternativas exemplificadas na Figura 10 é resultante do processo criativo manual, neste método de desenvolvimento de estampas as fotografias originárias da pesquisa de campo são impressas em diversos tamanhos em papel fotográfico, depois disto inicia a etapa de colagem manual e geração de um módulo de repetição. Embora as colagens geradas sejam escaneadas e o processo seja finalizado digitalmente com o rebatimento das imagens, constatou-se que os resultados obtidos perdem a qualidade devido ao método de impressão e escaneamento das colagens. Já a geração de alternativas resultantes do processo digital (Figura 11) possibilita mais variantes e as imagens não perdem a qualidade quando impressas em tecido.

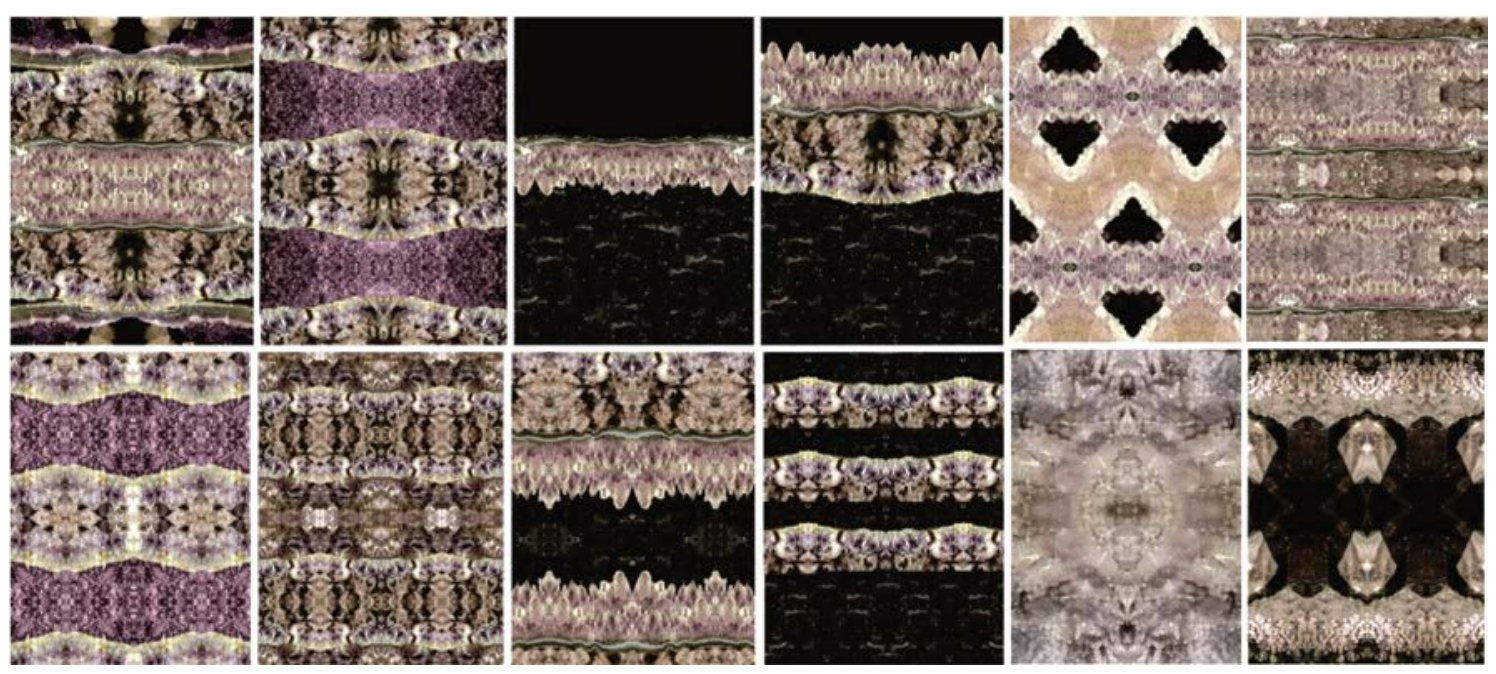

Figura 11 - Resultados - Processo Digital.

Fonte: Elaborado pelas autoras, 2015.

Conclui-se, por tanto, que os resultados da etapa manual foram satisfatórios, mas nem todos tornaram-se adequados para aplicação têxtil devido a falta de nitidez e qualidade das imagens. Os resultados obtidos com a fotografia trabalhada digitalmente foram então, escolhidos para impressão e confeç̧ão das peças. Além da alta qualidade, nesta fase de geração de estampas foi possível mesclar mais de uma gema, o que enriquece o resultado visual com mais cores, desenhos e texturas. 


\section{RESULTADOS}

A partir dos padrões gerados digitalmente no decorrer da fase de avaliação foram selecionadas estampas que realçam na composição os valores de continuidade dos desenhos e texturas das gemas, pensando que estes possam delimitar os contornos das peças de aplicação. Através de resultantes com paleta de cores semelhantes, que evidenciam em sua maioria as gemas de ametista, os desenhos e a organicidade dos materiais gemológicos foram incorporados ao segmento têxtil do design de superfície. $O$ resultado prático desta pesquisa inclui quatro embalagens em cetim com elastano, cada padrão em acordo com o produto estampado e confeccionado, dois conjuntos de biquínis (Figura 12) e duas collants (Figura 13), todas as peças produzidas por meio do processo de sublimação.
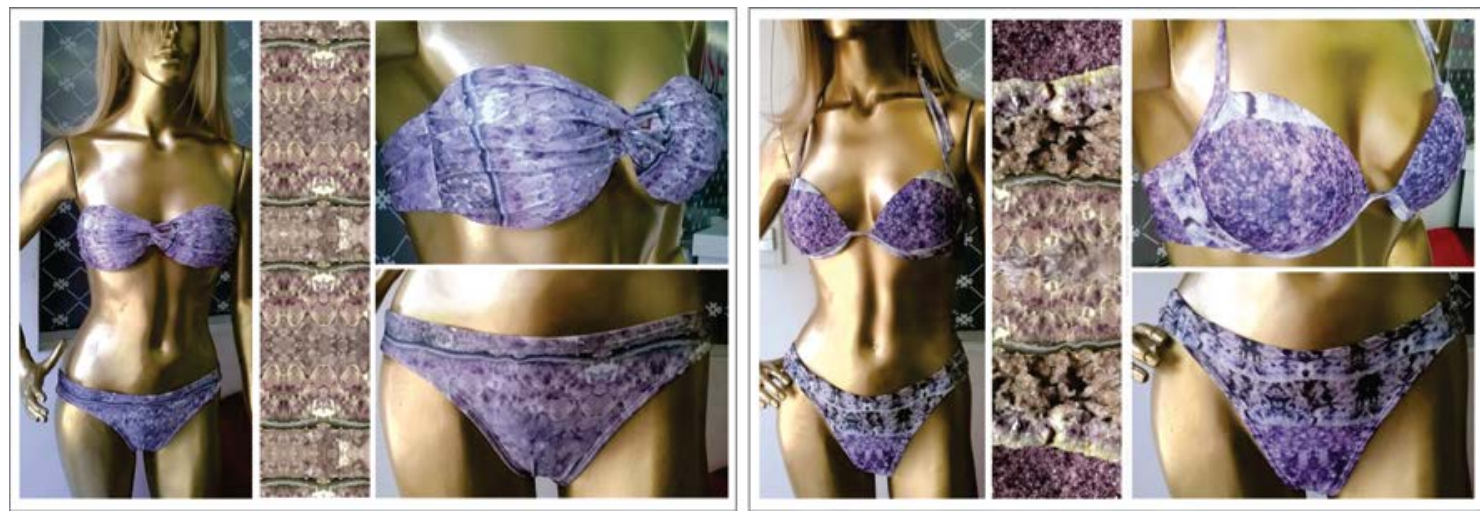

Figura 12 - Resultados III Biquíni.

Fonte: Elaborado pelas autoras, 2015.

Acredita-se que os resultados das composições e dos produtos capturaram a essência das variações lineares naturais. Em termos de estamparia os desenhos e lapidações de cada material gemológico proveniente da natureza torna-se uma fonte criativa de diversas possibilidades. Por mais que duas coleções selecionem a mesma gema como temática criativa, o resultado sempre vai ser singular, tanto pela variante do método utilizado como pelo próprio material de referência. Cada gema extraída da natureza detém desenho, coloração e textura únicos, detalhes como tonalidades e formatos podem até se assemelhar, contudo os materiais gemológicos além de raros se caracterizam pela beleza e particularidade, não existem duas gemas idênticas.
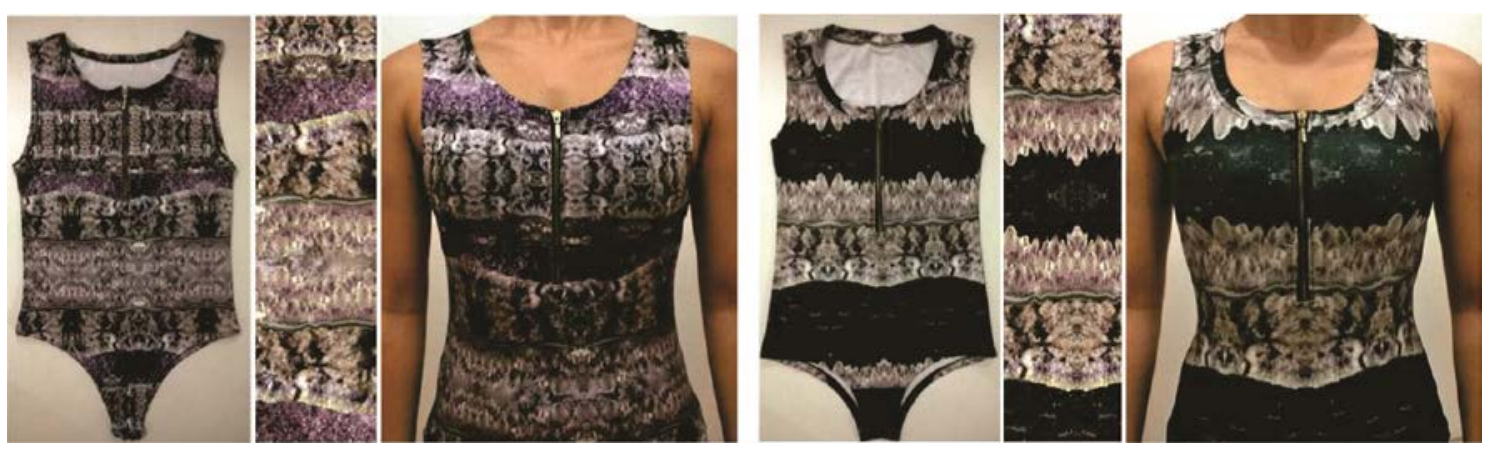

Figura 13 - Resultados IV Collant.

Fonte: Elaborado pelas autoras, 2015. 
Por meio da geologia há muitos outros elementos minerais da terra que ainda podem ser explorados. No decorrer desta pesquisa pode-se demonstrar alguns exemplos da gema como produto e como referencial criativo, denotando as possíveis transposições do palpável, da gema como elemento físico, a este recurso como fonte de inspiração na área criativa. A presente proposta não se deteve apenas na composição de superfícies por meio de um referencial, mas objetivou destacar um raro recurso natural, preservando e divulgando-o ao mesmo tempo. A busca por imagens autorais é uma das etapas mais significativas em termos de enriquecimento da pesquisa, deixar de usar uma imagem de domínio público e realizar a pesquisa de campo impacta positivamente na área, isto expõe aos demais pesquisadores possibilidades originais no design de superfície têxtil.

Os resultados demonstrados foram extremamente satisfatórios no sentido de expor algumas composições criativas possíveis através de uma temática ainda pouco usual. A partir de desdobramentos digitais, a estamparia pôde transformar a fotografia de materiais naturais em produtos têxteis ricamente detalhados. A geologia e a gemologia reafirmam a natureza como fonte criativa, poder transpor a natureza ou um produto já inserido no mercado em uma referência de tema para criação gera novos caminhos de pesquisa para área do design como um todo.

\section{CONCLUSÃO}

Muitas metas foram propostas no início da presente pesquisa; conclui-se ao término desta etapa, que os objetivos foram atingidos quase que em sua totalidade. $A$ principal finalidade deste estudo foi inserir a gema em uma pesquisa prático-teórica na área do Design de Superfície, investigando as potencialidades visuais dos materiais gemológicos como temática criativa. De ordem prática foi proposta a realização de uma pesquisa de campo para registro fotográfico de gemas e materiais gemológicos disponibilizados no Estado do Rio Grande do Sul, esta etapa foi concretizada e as imagens autorais utilizadas no desenvolvimento criativo das estampas. Em busca de melhores soluções estéticas, o processo criativo foi explorado tanto no âmbito manual, quanto no digital. A fase de experimentações também foi concluída com êxito, realizaram-se testes sobre as superfícies de papel, vidro, MDF e tecido, resultando em diferentes produtos exemplificados no decorrer desta pesquisa. O prosseguimento aos estudos práticos por meio do seguimento têxtil do design foi outro objetivo atingido. Em decorrência dos experimentos e produtos direcionados ao diversos segmentos que foram desenvolvidos acredita-se que esta pesquisa não termina aqui. Intui-se que esta tenha sido apenas mais uma etapa de um estudo teórico e prático que com certeza ainda tem muito desdobramentos a serem investigados.

\section{REFERÊNCIAS}

INSTITUTO BRASILEIRO DE GEMAS E METAIS PRECIOSOS (IBGM). Manual Técnico de

Gemas. 4 ed. rev. e atual. Brasília, 2009.

RUBIM, Renata. Desenhando a superfície. São Paulo: Ed. Rosari, 2010.

SCHUMANN, Walter. Gemas no Mundo. 9 ed. São Paulo: Disal, 2006.

WOODWARD, C. Guia das Pedras Preciosas. 2 ed. Lisboa: Presença, 2001 